\title{
Toxicological Effects of Pyrethroids Insecticide on the Spleen and Bone Marrow of Adult Albino Rats
}

\author{
${ }^{1} \mathrm{~K}$. A. Iteire, ${ }^{2}$ P. S. Igbigbi and ${ }^{10}$. Oyibororho \\ ${ }^{1}$ Department of Anatomy, University of Medical Sciences, Ondo State \\ 2Department of Anatomy, Delta State University, Abraka \\ [Corresponding Author: E-mail: afokeone@gmail.com; : : +2348037370122]
}

\section{ABSTRACT}

Pyrethroids are synthetic compounds chemically derived from the natural pyrethrins which are the insecticidal components of the pyrethrum extracts of chrysanthemum flower. The aim of this study was to investigate the toxicological effects of pyrethroid insecticide "Mortein" (M) on the bone marrow and spleen of adult Wistar rats. Twenty five adult rats $(150-200 \mathrm{~g})$ were purchased from the animal facility of the College of Health Sciences, Delta State University, Abraka and assigned into five groups $(n=5)$. Groups I, II and III were treated orally with $2250 \mathrm{mg} / \mathrm{kg}$ of Mortein insecticide suspended in olive oil once daily for 7, 21 and 40 days respectively. Groups IV and $V$ were administered tap water and olive oil respectively, once daily throughout the duration of experiment. At the end of each respective durational treatment, the rats were euthanized. The spleen and bones were harvested and processed for histological analysis using standard techniques. The resultant sections were stained with Haematoxylin and Eosin (H\&E) and analyzed with the aid of a light microscope for histological changes. Histological examination of the bone marrow of the treated rats revealed extensive congestion that was time dependent as well as hypo cellularity when compared to the oil and normal control groups. The rats' spleens were markedly congested and there were intra-parenchyma hemorrhages of varying degrees compared to the rats of control groups. $\mathrm{M}$ insecticide at the dosage considered, was highly toxic to both spleen and bone marrows of rats for the different durations considered and the effects observed were time-dependent.

Key words: Toxicology, Mortein, Pyrethroids, Spleen, Bone Marrow, Insecticide, Rats

\section{INTRODUCTION}

Pyrethroids are synthetic compounds chemically derived from the natural pyrethrins which are the insecticidal components of the pyrethrum extracts of chrysanthemum flower. They are among the most recent groups of pesticides currently in the market and account for a large percentage of the pesticides employed domestically today. These agents are widely used for control of domestic insects and ectoparasites in both veterinary and human medicine (Diaz, 2015). This may have influenced a sudden increase in their use hence, potential for daily exposure (Smith et al., 2002; Zhang et al., 1991). Studies have revealed chemical residues of several pyrethroids in urine samples of some individuals of a settlement with no known exposure (Schettgen et al., 2002; Heudorf and Angerer, 2001). Schettgen et al. (2002) suggests that majority of the contamination observed was as a result of ingestion of food contaminated with pyrethroids (Schettgen et al., 2002). Furthermore, the Center for Disease Control and Prevention (CDC) third National Report on Human Exposure to Environmental Chemicals revealed human exposure to these agents. These studies revealed that humans are exposed to several pyrethroids pesticides via direct use, dietary means and occupational exposure thereby making oral route one of the major means of exposure to these chemicals (Heudorf and Angerer, 2001). The immune system which also includes the bone marrow and spleen had been observed to be least considered in toxicological studies involving pyrethroids. This is because certain studies have previously shown that serum of rats contained carboxylesterase which has the ability to break down pyrethroids hence making blood a major site of pyrethroids metabolism (Anand et al., 2006; Mirfazalian et al., 2006). However, since this enzyme is found only in the serum, there is the possibility of other tissues/organs suffering from pyrethroids toxicity. Some studies have demonstrated that many of the commonly used pesticides can suppress the immune system and result in increased 


\section{Iteire et al: Toxicological Effects of Pyrethroids Insecticide on the Spleen and Bone Marrow of ...}

toll of infectious agents. Studies have also shown that short-term exposure to 2,3,7,8 -Tetrachlorodibenzo-pdioxin (TCDD) resulted in thymus and spleen atrophy as well as cellular depletion of bone marrow via apoptosis (Kerkvliet et al., 1994; McConkey et al., 1994). Mortein (M) Insecticide is made up of d-trans Allethrin $(0.10 \% \mathrm{w} / \mathrm{w})$, Imiprothrin $(0.02 \% \mathrm{w} / \mathrm{w})$ and $\mathrm{d}$ phenothrin $(0.03 \% \mathrm{w} / \mathrm{w})$ as active ingredients. Although there is a common perception by users about the general safety of pyrethroids insecticides, several studies have reported their toxic effects (Sangha et al., 2011; Inayat et al., 2007; Kamal et al., 2007). It is also believed that insecticides generally have adverse effects with prolonged exposure, mostly when they are mixed to complement their modes of action, as seen in $M$ insecticide. According to Gosselin, some of these agents are often formulated with oils or petroleum distillates and packaged in combination with synergists such as piperonyl butoxide (PBO) and n-octyl bicycloheptene dicarboximide, thereby rendering them more toxic and prone to causing diseases (Gosselin, 1984). Therefore the purpose of this study was to investigate the toxicological effects of Pyrethroids pesticide $\mathrm{M}$ on the bone marrow and spleen of adult Albino rats.

\section{MATERIALS AND METHODS}

The present study involved the use of experimental study design. Approval for the study was received from the Research Ethics Committee of the Faculty of Basic Medical Sciences, Delta State University Abraka and the experiment was conducted accordingly as proposed by the guidelines for the care and use of animals for experiment set by W.H.O.

\section{Animals Selection}

Twenty five (25) adult Albino rats of both sexes were acquired from the animal house of the College of Health Sciences, Delta state University Abraka. The rats were healthy and weighed $150-250 \mathrm{~g}$ prior to the start of the treatment. On transfer to the experimental location the rats were allowed to acclimatize for two weeks under favorable atmospheric conditions and fed with standard rat feeds and water ad libitum.

\section{Test Compound}

The chemical product composed of Allethrin, Imiprothrin and Phenothrin was purchased from Abraka Main Market, Abraka, Delta State. It was manufactured by Rekitt Benckiser Nigeria Limited, Agbara Ogun State and registered with National Agency for Food and Drug Administration Control (NAFDAC) with number 048724.

\section{Pesticide Preparation}

The pesticide was diluted with Olive oil to give $75 \%$ of the product and a single sub-lethal dose of $2250 \mathrm{mg} / \mathrm{kg} / \mathrm{bw}$ of rats was calculated and orally administered to the rats for three different durations respectively (Table I).

Grouping and Treatment of Rats (Modified from Iteire et al., 2015)

Twenty five rats were randomly divided into five groups of five animals each and properly identified. All rats were housed in compartmented iron cages in a room, under favorable conditions. Prior to the time of administration of the drug, the male and female rats were kept in different compartments to avoid mating. The rats of normal control group IV were treated with tap water as placebo; olive oil was given to the rats in group $V$ (oil control group) whereas the chemical was administered to rats of the treatment groups (group I-III) via oral route by the use of improvised cannula.

\section{Euthenization of Animals and Samples Collection}

At the end of the respective duration of treatment for each group, the rats were euthanized by cervical dislocation, incised in their abdomen and their spleens harvested. All fleshy tissues were removed from the long bones of the rats, after which the bones were fixed. The harvested tissues were grossly examined and then fixed with normal saline.

\section{Tissues Processing}

The bones were decalcified using chelating agents and standard manual tissue processing procedures were employed on both bony and splenic tissues.

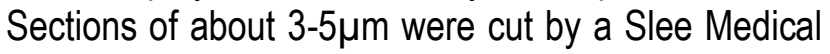
rotary microtome and stained with hematoxylin and eosin (H\&E) (Carlton, 1967). Slides were examined with the aid of a light microscope for histological 


\section{Nigerian Journal of Basic and Applied Science (December, 2017), 25(2): 143-150}

variations and were consequently captured on a Brunel light microscope, 20 mega pixels (Brunel SP35 Digital Trinocular).

\section{RESULTS}

\section{Effects of "M" on the Bone Marrow}

In the index study, administration of $2250 \mathrm{mg} / \mathrm{kg} / \mathrm{bw}$ of M pesticide for 7 days to Wistar rats caused mild reductions in marrow and fats of bone marrows (Fig 2) when compared to those of the control group (Fig 1). The same treatment for
21 days also resulted in mild reductions in marrows as well as fats, and there was moderate hypo cellularity with reductions in the number of megakaryocytes (Fig 3) compared to the control group. When the rats were further treated for longer duration of 40 days with the same treatment, similar histological alterations were noticed in the other two groups observed. Furthermore, there were extensive and marked proliferations of congested blood vessels (Fig 4).

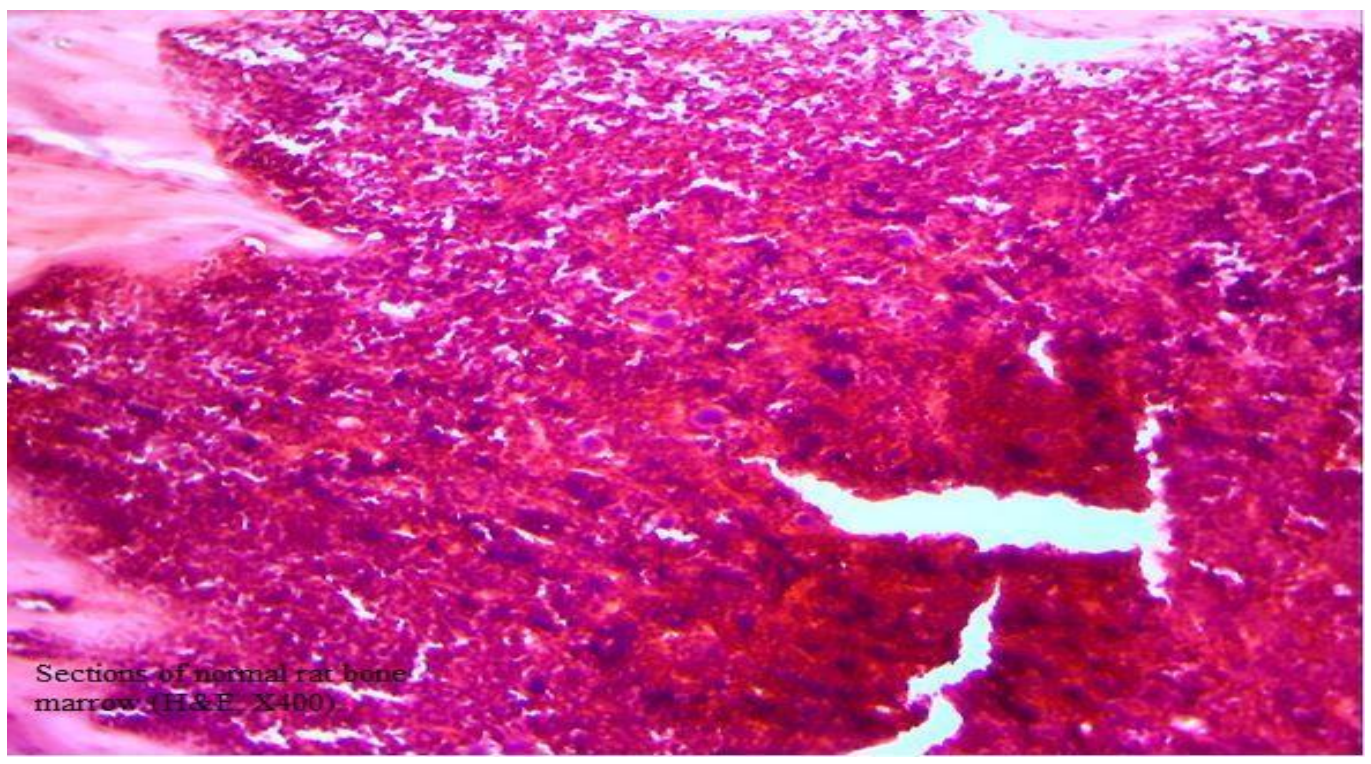

Fig. 1: Sections of normal rat bone marrow (H\&E, X400).

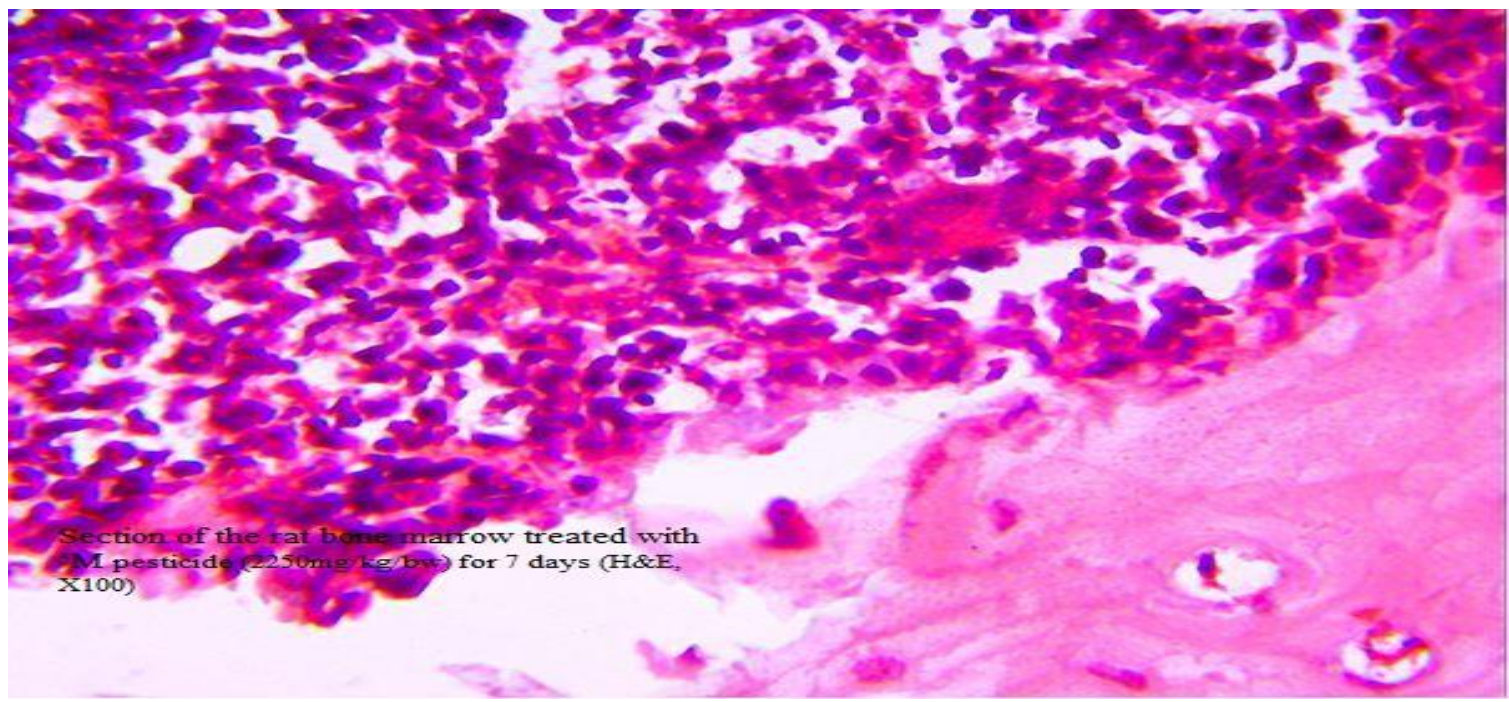

Fig. 2: Section of the rat bone marrow treated with 'M pesticide $(2250 \mathrm{mg} / \mathrm{kg} / \mathrm{bw})$ for 7 days (H\&E, X100) 


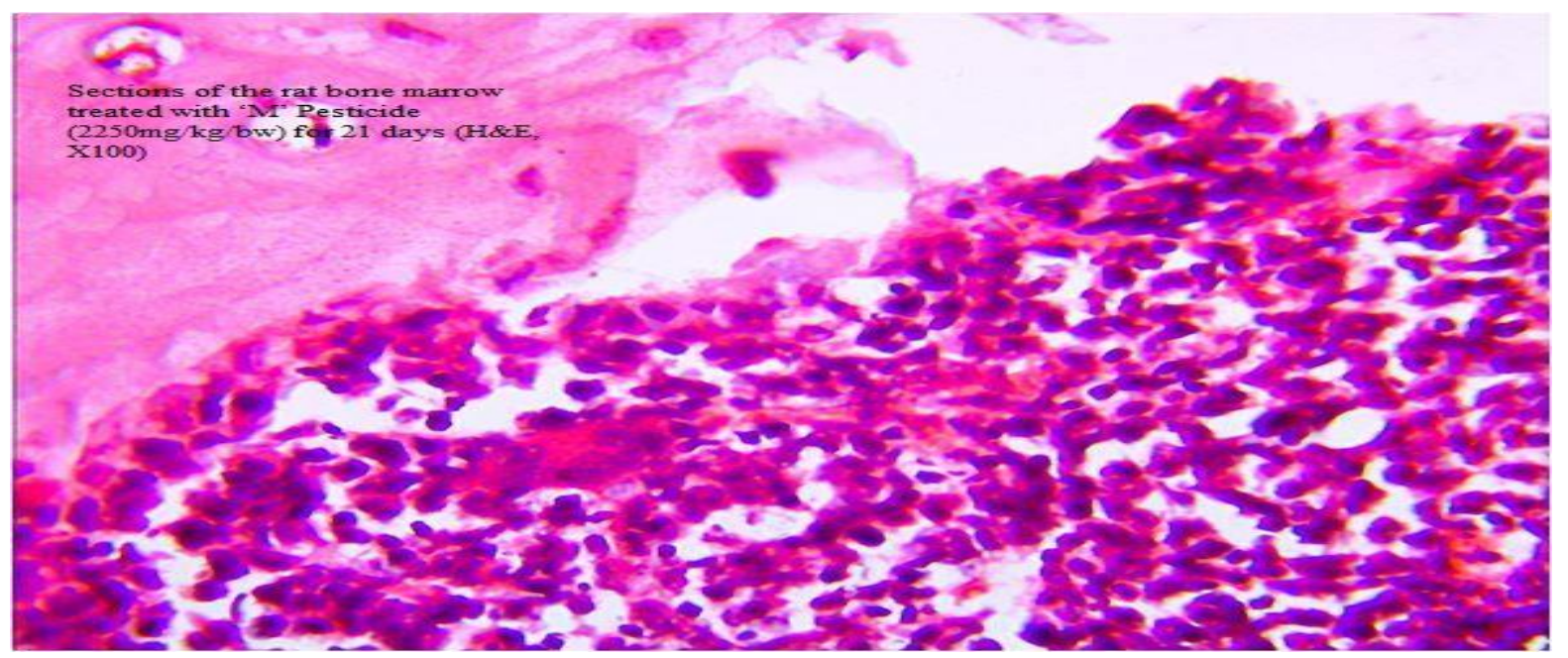

Fig. 3: Sections of the rat bone marrow treated with 'M' Pesticide (2250mg/kg/bw) for 21 days (H\&E, X100)

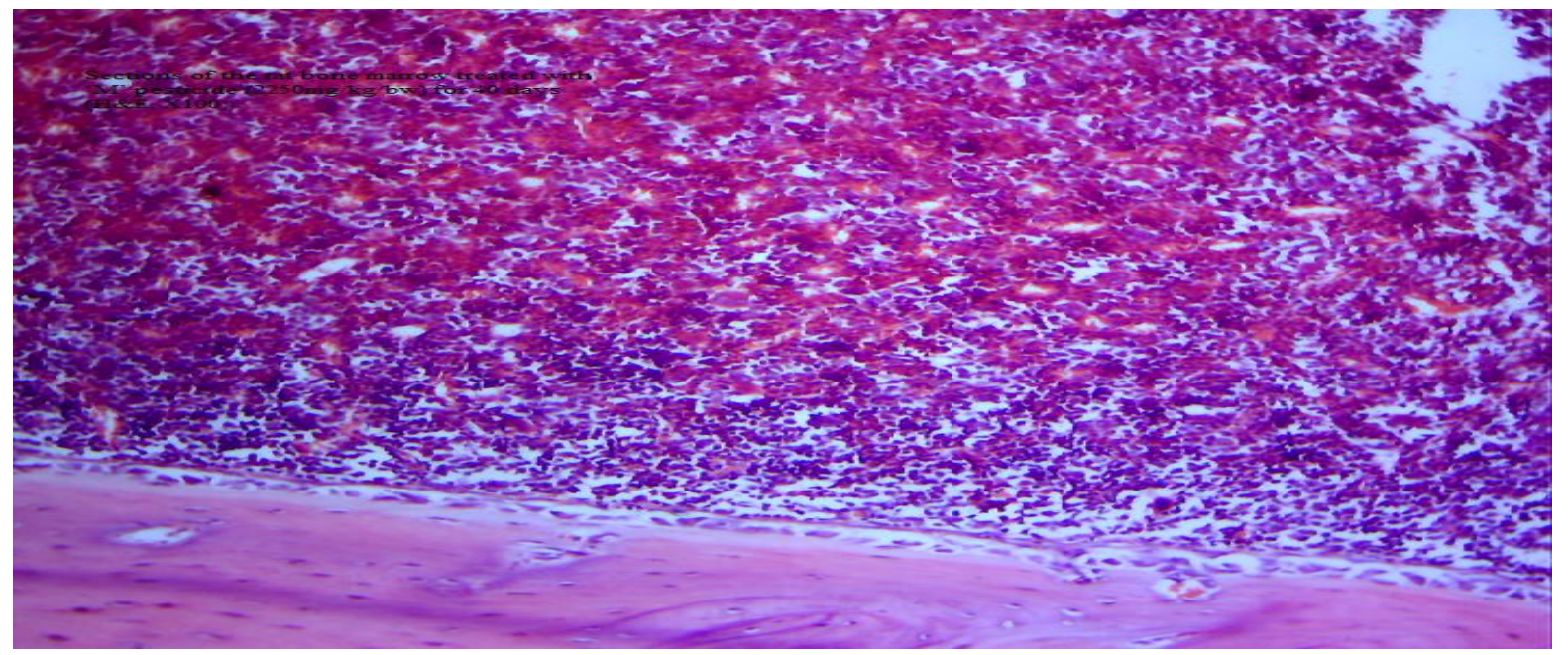

Fig. 4: Sections of the rat bone marrow treated with ' $M$ ' pesticide $(2250 \mathrm{mg} / \mathrm{kg} / \mathrm{bw}$ ) for 40 days (H\&E, $\mathrm{X} 100)$

\section{Effects of "M" on the Spleen}

Treatment with $2250 \mathrm{mg} / \mathrm{kg} / \mathrm{bw}$ of M pesticide for 7 days caused the rats' spleen to show moderate congestion and intra-parenchyma hemorrhage (Fig 6) when compared to rat spleen of the control group (Fig 5). With same treatment for longer duration of 21 days, the congestions and intra-parenchyma hemorrhages observed were marked (Fig 7) when compared to those of the control group (Fig 5). Longer duration of 40 days resulted in extensive congestions and hemorrhages in the rats' spleen.

These findings suggest a time-dependent effect of $M$ pesticide on both the spleen and bone marrow of adult Wistar rats. 
Nigerian Journal of Basic and Applied Science (December, 2017), 25(2): 143-150

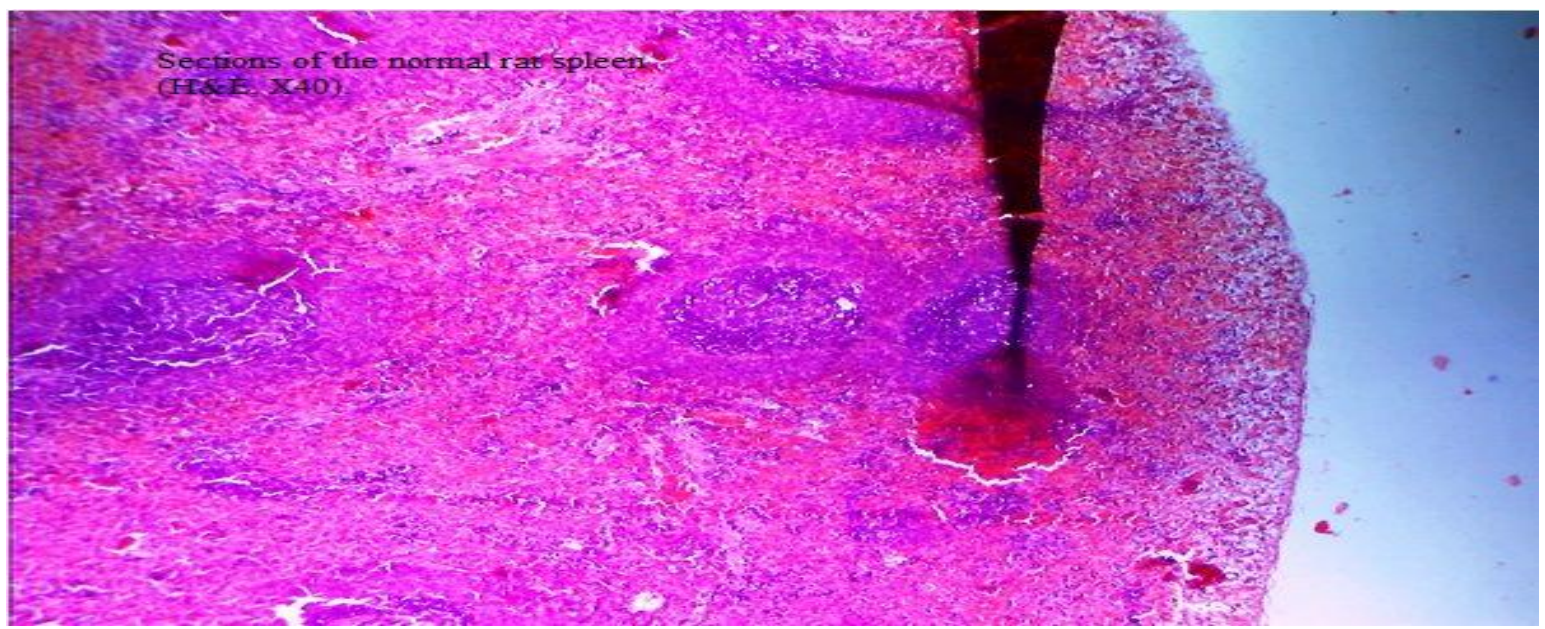

Fig. 5: Sections of the normal rat spleen (H\&E, X40)

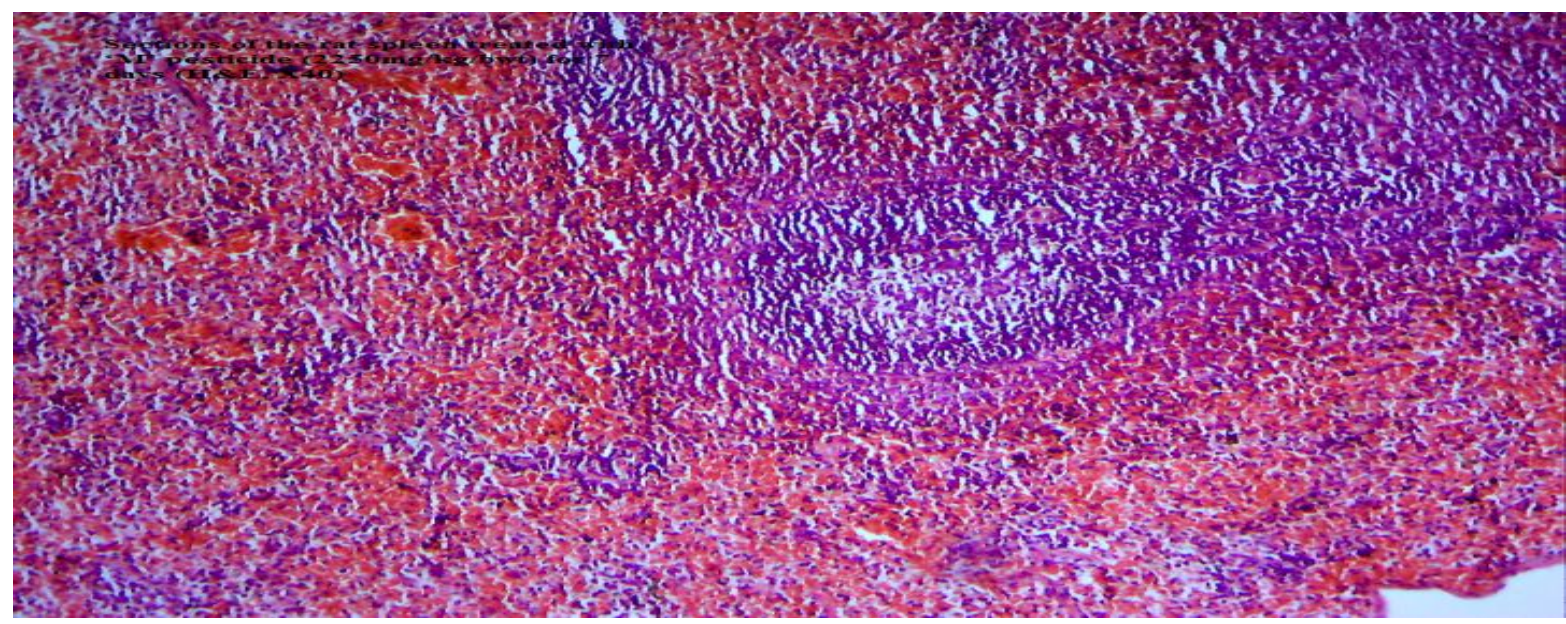

Fig. 6: Sections of the rat spleen treated with 'M' pesticide (2250mg/kg/bwt) for 7 days (H\&E, X40)

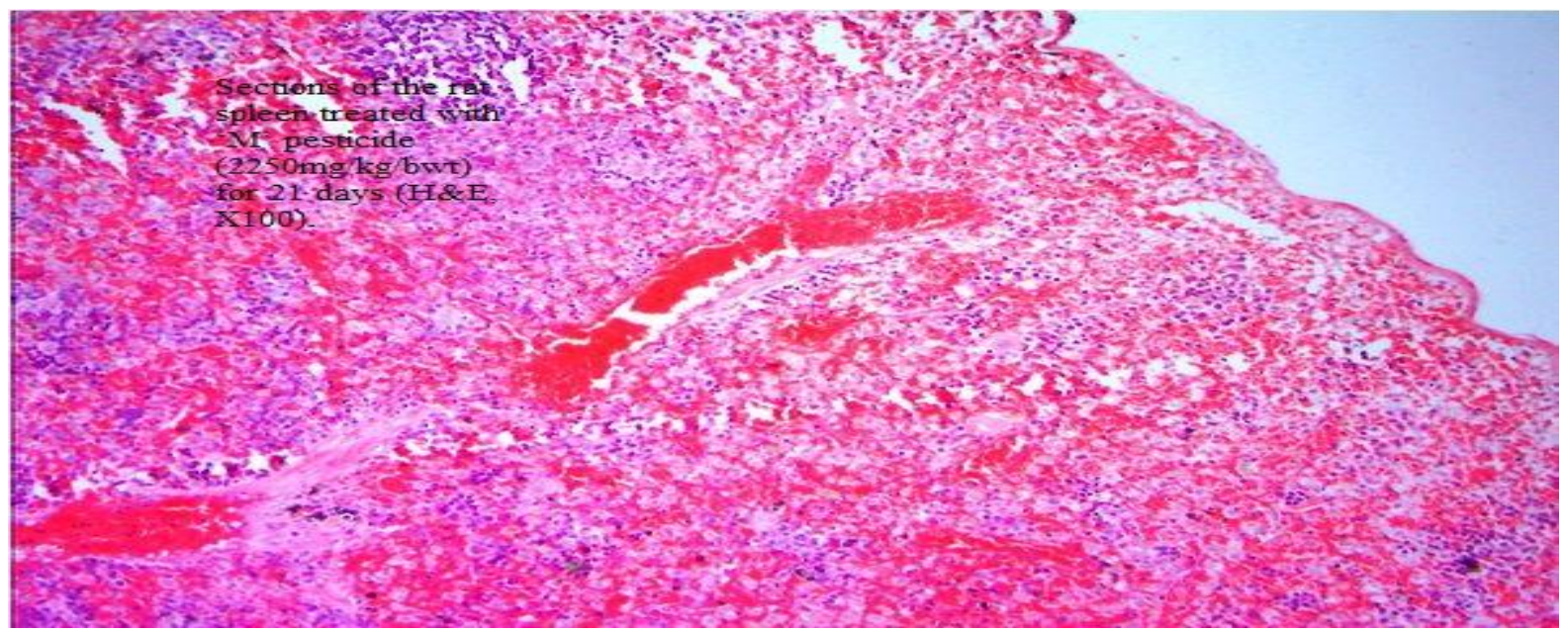

Fig. 7: Sections of the rat spleen treated with 'M' pesticide $(2250 \mathrm{mg} / \mathrm{kg} / \mathrm{bwt})$ for 21 days (H\&E, X100). 


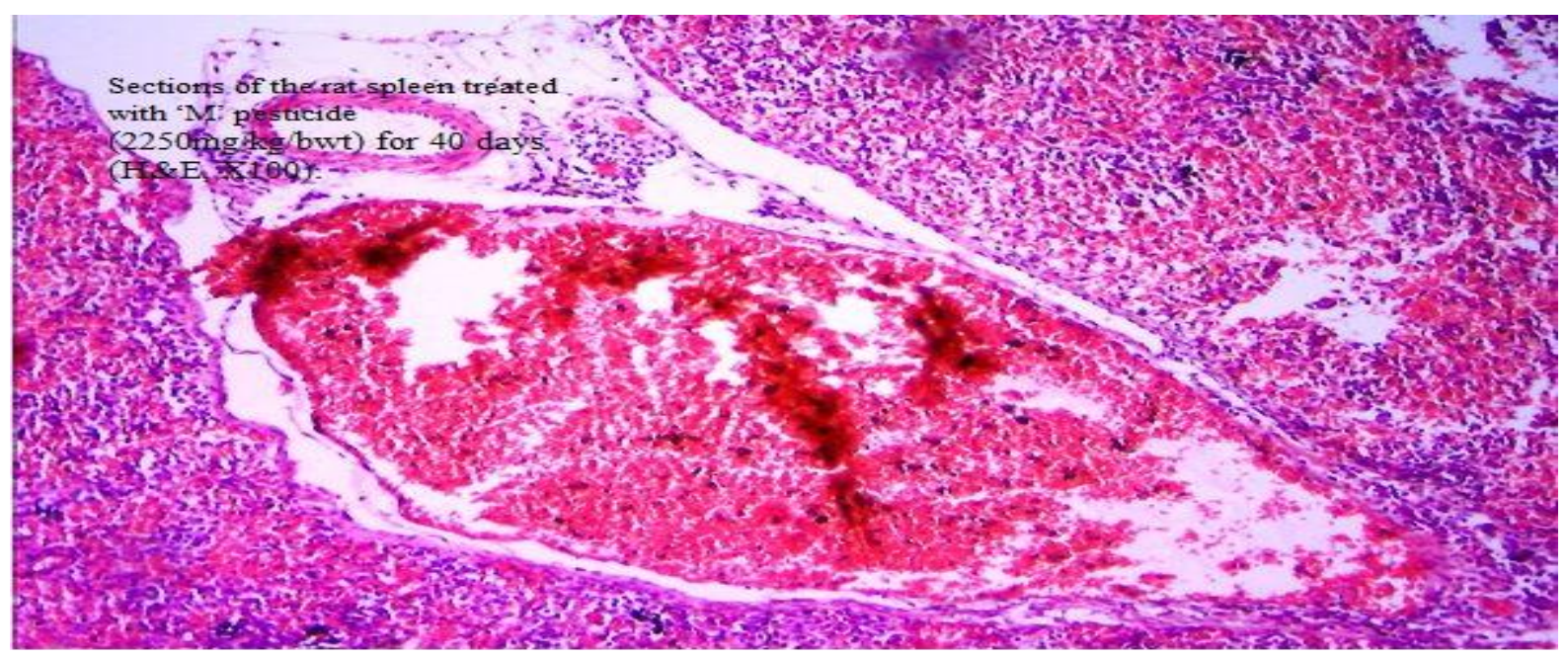

Fig. 8: Sections of the rat spleen treated with ' $M$ ' pesticide $(2250 \mathrm{mg} / \mathrm{kg} / \mathrm{bwt})$ for 40 days (H\&E, X100)

\section{DISCUSSION}

The rats mostly affected by this agent were those administered for 40 days; suggesting that prolonged exposure to the aforementioned pyrethroids influences haemapoiesis. Hypo-cellularity of bone marrow and pancytopenia are characteristics of aplastic anemia which may be secondary to development of hepatitis (Rosario et al., 2009). In most cases of severe liver disease, decreased production of plasma protein could lead to extensive hemorrhages (Pereira et al., 1996). Iteire et al. (2005) had earlier reported severe congestion of intervening blood vessels of rats lungs treated with this agent. Hence, we can infer from this study that anemia could be a risk factor in rats exposed to $\mathrm{M}$ pesticide. Moreover, the extensive proliferation of blood vessels observed, especially in rats administered for the longest duration is in conformity with the work of (Luty et al., 2000) who reported deltamethrin and fenvalerate stimulated erythropoiesis and synthesis of $\mathrm{Hb}$ in male mice. This could definitely result from the presence of cyano-groups in all type II pyrethroids (allethrin, imoprothrin) which may reduce the oxygen carrying capacity of blood leading to reduced metabolism. Consequently, decreased oxygen circulation in the blood will cause a feedback loop on the kidney to produce erythropoietin which acts on bone marrow to produce more blood which continues until the marrow becomes over stressed and unable to regenerate loss cells thereby leading to hypo-cellularity in the bone marrow.

The marked congestions and intra-parenchyma hemorrhages observed in the spleen were similar to that observed in the bone marrow biopsies. Hypersplenism with characteristic splenomegaly has also been previously associated with portal hypertension which is another mechanism of anemia in chronic liver disease (Rosario et al., 2009). Consequently, the congestion observed in the spleen may be as a result of intra-splenic destruction of erythrocytes (Pereira et al., 1996). These findings are in agreement with previous studies reporting thymus and spleen atrophy as well as cellular depletion in bone marrow caused by accelerated apoptosis in animals treated with TCDD (Kerkvliet et al., 1994; McConkey et al., 1994). Prater et al. (2002) had earlier reported that a single dose tropical exposure of permethrin adversely affected the function of immune organs likesuch as spleen and thymus. Also, Banerjee and Hussain, (1987) observed that endosulfan depressed humoral and cell- mediated immunity in rodents at very low doses that do not show any other overt signs of toxicity. Similarly, hepatic lesions leading to congestion and hemorrhages of spleen treated with profenofos and chlorpyrifos has been reported (EL-bendary et al., 2004). Therefore our results had further confirmed hemorrhages of spleen of rats treated with pyrethroids pesticide. 


\section{CONCLUSION}

$\mathrm{M}$ pesticide at the dose considered, was toxic to both spleen and bone marrow of rats for the three different periods of treatment considered in this study. Therefore, haematological studies should be carried out to assess how its toxicity influences blood parameters such as Parked Cell Volume (PCV) and White Blood Cell count (WBC) etc. to ascertain possible anemic effects from these agents.

\section{ACKNOWLEDGEMENT}

The authors acknowledge Dr E.I. Odokuma, Mr. Victor Ekudina, Kesseina, Roland Atumah, and Monica for their assistance during the collection of samples and histological analysis.

\section{REFERENCES}

Anand, S.S., Bruckner, J.V., Haines, W.T., Muralidhara, S., Fisher, J.W. and Padilla, S. (2006). Characterization of deltamethrin metabolism by rat plasma and liver microsomes. Toxicology and Applied Pharmacology, 212: 156-166.

Banerjee, B.D. and Hussain, Q.Z. (1986). Effect of Sub-chronic Endosulfan Expossure on Humoral and Cell-mediated Immune Responses in Albino Rats. Archives of Toxicology. 59(4): 279-284.

Banerjee, B.D. and Hussain, Q.Z. (1987). Effects of Endosulfan Expossure on Humoral and Cell-mediated Immune Responses in Rats. Bulletins of Environmental Contaminants and Toxicology, 38(3): 435-441.

Carlton, S.M. (1967). Text Book of Histochemical Techniques $4^{\text {th }}$ ed. Oxford University Press. Pp 48-137.

Diaz, J.H. (2016). Chemical and Plant-Based Insect Repellents: Efficacy, Safety, and Toxicity Wilderness Environmental Medicine. pii: S1080-6032(15)00434-2. doi: 10.1016/j.wem.2015.11.007.

EL-bendary, H.M., Shaker, M.H., Saleh, A.A. and Negm, S.E. (2004). Histopathological Changes Associated with Exposure of Male Mice to Profenofis and Chlorpyrifos.
Annual Research and Review in Biology. 4(5):2347-565.

Gosselin, R.E. (1984). Clinical Toxicology of Commercial Products. Williams and Wilkins. Baltimore, MD. Pp 1024 1030.

Heudorf, U. and Angerer, J. (2001). Metabolites of pyrethroid insecticides in urine specimens: current exposure in an urban population in Germany. Environmental Health Perspectives, 109(3): 213-217.

Inayat, Q., Ilahi, M. and Khan, J. (2007). A morphometric and histological study of the kidney of mice after dermal application of cypermethrin. Journal of Pakistan Medical Association, 57: 587591.

Iteire, A.K, Igbigbi, P. and Ajileye A.B. (2015). Histological assessment of the Effects of Pyrethroids insecticide Mortein on the Lungs of Adult Wistar Rats. IORS Journal of Dental and Medical Science, 14(1):37-80.

Kamal, S.M., Khan, A., Rizvi, F. and Sadeeq-UrRehman. (2007). Effect of Cypermethrin on Clinic-Hematological Parameters in Rabbits. Pakistan Veterinary Journal, 27:171-175.

Kerkvliet, N. and Burleson, G.R. (1994). Immunotoxicity of TCDD and related halogenated aromatic hydrocarbons. In: Dean, J.H., Luster, M.I., Munson, A.E., Kimber, I.; Immunotoxicology and Immunopharmacology. 2nd ed. Raven Press: New York, Pp 97-122.

Mirfazalian, A., Kim, K.B., Anand, S.S., Kim, H.J., Tornero-Velez, R., Bruckner, J.V. and Fisher, J.W. (2006). Development of a physiologically based pharmacokinetic model for deltamethrin in the adult male Sprague-Dawley rat. Toxicological Science. 93:432-442.

Laffi, G., Marra, F., Taquini, R. and Abbate, R. (2006). Coagulation Defects in CirrhosisOld Dogmas not Yet Ready for Burial. Journal of Thrombosis and Haemostasis, 4: 2068-2069. 
Luty, S., Latuszynska, J., ObuchowskaPrzebirowska, D., Tokarska, M. and Haratym-Maj, A. (200). Subacute Toxicity of Orally Applied à-Cypermethrin in Swiss Mice. Annals of Agricultural and Environmental. Medicine. 7:33-41.

McConkey, D.J., Jondal, M.B. and Orrenius, S.G. (1994). Chemical induced apoptosis in the immune system. In: Dean, J.H., Luster, M.I., Munson, A.E., Kimber, I.; Immunotoxicology and Immunopharmacology. 2nd ed. Raven Press: New York, Pp 473- 486.

Pereira, S.P., Langley, P.G. and Williams, R. (1996). The Management of Abnormalities of Hemostasis in Acute Liver Failure. Seminars in Liver Disease. 16:403-414.

Prater, M.R.., Gogal, R.M., Blaylock, B.L., Longstreth, J. and Holladay, S.D. (2002). Single-dose topical exposure to the pyrethroid insecticide, permethrin in C57BL/6N mice: effects on thymus and spleen. Food Chemistry and Toxicology, 40(12): 1863-1873.

Rosario, G.C., Jones, E.A. and Moreno-Otero, R. (2009). Spectrum of anemia associated with chronic liver disease. World Journal of Gastroenterology. 15(37): 4653-4658.

Sangha, G.K, Kaur, K., Khera, K.S. and Singh, B. (2011). Toxicological Effects of Cypermethrin on Female Albino Rats. Toxicology International, 18: 5-8.

Schettgen, T., Heudorf, U., Drexler, H. and Angerer, J. (2002). Pyrethroid exposure of the general population- is this due to diet? Toxicology Letters, 134: 141-145.

Smith, P.A., Thompson, M.J. and Edwards, J.W. (2002). Estimating occupational exposure to the pyrethroid termiticide bifenthrin by measuring metabolites in urine. Journal of Chromatography B, 778: 113-120.

Zhang, Z., Sun, J., Chen, S., Wu, Y. and He, F. (1991). Levels of exposure and biological monitoring of pyrethroids in spraymen. British Journal of Industrial Medicine, 4: 82-86. 